\title{
Surgical Treatment of Spontaneous Intracerebral Hemorrhage in a Full-term Infant With Coagulopathy
}

-Case Report-

\author{
Shunichi YOKOYAMA, Kenji TAKAYAMA, Takahiro MURAKAMI, \\ Yasunari ISHIKAWA, Naoki FUJIWARA*, and Hitoshi GANAHA*
}

Divisions of Neurosurgery and * Pediatrics, Okinawa Chubu Hospital, Gushikawa, Okinawa

\begin{abstract}
An 11-week-old male infant presented with intracerebral hemorrhage associated with coagulopathy manifesting as left hemiparesis, lethargy, and vomiting. Computed tomography demonstrated extensive right frontoparietal intracerebral hemorrhage extending into the ventricular system. Liver function tests revealed abnormal values of transaminases and bilirubin. Blood coagulation studies showed prolonged prothrombin time (PT) and activated partial thromboplastin time (APPT). PT and APTT immediately normalized after the administration of vitamin $K$ and fresh frozen plasma. Right parietal craniotomy and evacuation of the hematoma were performed because of the deterioration in consciousness and left hemiparesis. No vascular abnormality was observed in the hematoma cavity. After surgery, he became alert and the left hemiparesis improved. There is a risk of intracerebral hemorrhage due to vitamin $\mathrm{K}$ deficiency even if prophylactic administration of vitamin $\mathrm{K}$ was given. Surgical treatment should be considered for the treatment of infantile spontaneous intracerebral hemorrhage, especially if neurological deterioration is present.
\end{abstract}

Key words: coagulopathy, infant, intracerebral hemorrhage, surgery, vitamin K deficiency

\section{Introduction}

Spontaneous intracerebral hemorrhage in full-term neonates and infants is rare, but occurs in the absence of identifiable risk factors in most cases. ${ }^{3,5,11 \text {, }}$ 13,15) The risk factors for intracranial hemorrhage in neonates are premature birth, birth asphyxia, and birth trauma. ${ }^{13)}$ Spontaneous intracerebral hemorrhage in early infancy usually occurs in breast-fed infants at 3 to 8 weeks of age, and is usually caused by vitamin $\mathrm{K}$ deficiency, whereas other causes are rare. ${ }^{14)}$

The incidence of vitamin K deficiency in infancy has decreased remarkably in Japan, due to the increasingly widespread prophylactic administration of vitamin $\mathrm{K}$ during the neonatal period, but cases of vitamin $\mathrm{K}$ deficiency during or after the neonatal period still occur.7)

We report a case of intracerebral hemorrhage associated with coagulopathy treated by surgery in a full-term ( $>2500 \mathrm{~g}$ birth weight, 37 weeks gestational age) infant who had received prophylactic

Received June 24, 2002; Accepted October 16, 2002 administration of vitamin $\mathrm{K}$.

\section{Case Report}

An 11-week-old male infant was born on May 9, 2001, at 38 weeks of gestation, by spontaneous vaginal delivery to a 40-year-old woman. The pregnancy, labor, and delivery were uncomplicated. Vitamin K was administered on the day of birth, and at age 5 days and 1 month.

He presented with lethargy and vomiting on July 28, 2001 at the emergency department of Chubu Hospital. Physical examination found he was lethargic, with a head circumference of $40 \mathrm{~cm}$ and isocoric pupils, but no evidence of head trauma. Neurological examination found slight left hemiparesis. He had mild jaundice.

Transfontanel ultrasonography in the emergency room revealed a hyperechoic mass in the frontoparietal region. Computed tomography (CT) confirmed extensive right frontoparietal intracerebral hemorrhage extending into the ventricular system (Fig. 1A). Laboratory studies revealed a white blood cell count of $14,500 / \mu$ l with a normal differential 


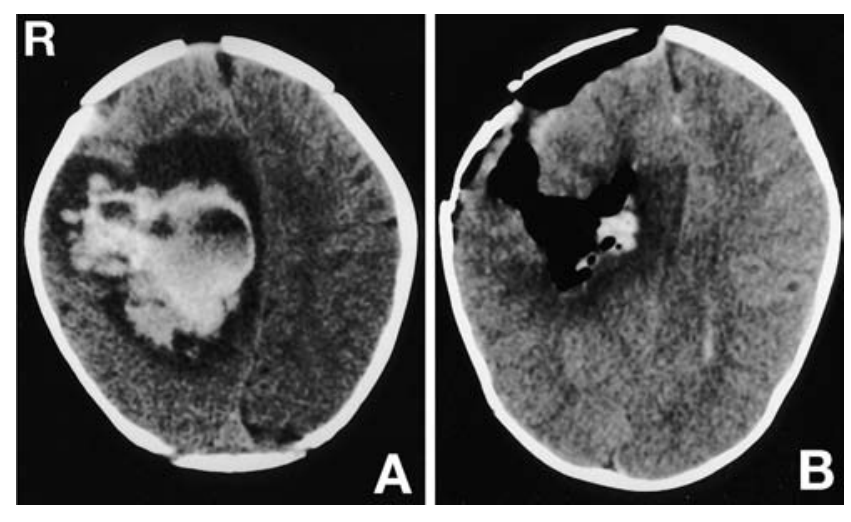

Fig. 1 A: Preoperative computed tomography (CT) scan demonstrating extensive right frontoparietal intracerebral hemorrhage. B: Postoperative CT scan confirming evacuation of the hematoma.

count and a platelet count of $375,000 / \mu \mathrm{l}$. Liver function tests showed aspartate aminotransferase $176 \mathrm{IU} / \mathrm{l}$ (normal 10-34 IU/l), alanine aminotransferase $182 \mathrm{IU} / \mathrm{l}$ (normal 7-35 IU/l), total bilirubin $6.3 \mathrm{mg} / \mathrm{dl}$ (normal $0.2-1.2 \mathrm{mg} / \mathrm{dl}$ ), and direct bilirubin $4.8 \mathrm{mg} / \mathrm{dl}$ (normal $0.0-0.4 \mathrm{mg} / \mathrm{dl}$ ). Results of blood coagulation studies were abnormal, with a prothrombin time (PT) of 56.4 sec (normal 10-13 sec) and an activated partial thromboplastin time (APPT) of $101.8 \mathrm{sec}$ (normal 23-35 sec). The hepaplastin test showed the coagulation activity was less than detectable (normal 70-130\%). PT and APTT immediately normalized after the administration of vitamin $\mathrm{K}$ and fresh frozen plasma.

The patient underwent a right parietal craniotomy and evacuation of the hematoma because of the deterioration in consciousness and left hemiparesis. The hematoma was evacuated without difficulty during hemostasis. No vascular abnormality was observed in the hematoma cavity.

Postoperative CT confirmed the evacuation of the hematoma (Fig. 1B). The postoperative course was uneventful. He became alert and the left hemiparesis improved. The values of PT, APTT, and the hepaplastin test remained in the normal range without further treatment. Neurological examination found only very slight left hemiparesis at age 13 months.

\section{Discussion}

Infants with vitamin $\mathrm{K}$ deficiency are breast-fed infants of 3 to 8 weeks of age, and have a bleeding tendency which disappears after vitamin $\mathrm{K}$ treatment. ${ }^{14)}$ Our patient was breast-fed, showed a bleeding diathesis, and vitamin $\mathrm{K}$ and fresh frozen plasma corrected his abnormal PT and APTT values, consistent with vitamin $\mathrm{K}$ deficiency ${ }^{6}{ }^{6}$ Liver function tests suggested a hepatic disorder. Defects in the enterohepatic circulation interfere with the absorption of fat-soluble vitamins in the ileum. ${ }^{6)}$ Coagulopathy probably occurred in our patient because of the malabsorption of vitamin $\mathrm{K}$ caused by the transient liver dysfunction, and resulted in intracerebral hemorrhage. Therefore, there is a risk of intracerebral hemorrhage despite the prophylactic administration of vitamin $\mathrm{K}$.

Clinical symptoms of perinatal intracerebral hemorrhage, irrespective of the specific location of the bleeding, include cardiorespiratory problems, arterial hypotension, and neurological disturbances such as lethargy, seizures, and loss of archaic reflexes. ${ }^{1)}$ The initial symptoms in our patient were lethargy and vomiting. Cranial ultrasonography provides rapid and accessible diagnostic information in patients with these nonspecific symptoms which may not be immediately available with other neuroimaging methods. ${ }^{12)}$ Care should be taken in the diagnosis of infantile intracerebral hemorrhage because the clinical symptoms may be vague and nonspecific. Transfontanel ultrasonography and subsequent CT can provide a rapid and accurate diagnosis. ${ }^{1)}$

The prognosis for patients treated conservatively is usually good even if extensive hemorrhage is observed by the initial CT.2,4,10,12,14) However, subsequent developmental progression was poor in some patients despite adequate control of intracranial hypertension. ${ }^{8)}$ Surgical evacuation was not important in the management of the majority of previous patients..$^{910,15)}$ However, the majority of a large series of full-term neonates and infants with intracerebral hemorrhage were managed surgically. ${ }^{15}$ The primary indication for surgical intervention was extensive hemorrhage with radiographic evidence of mass effect in a symptomatic infant. The very young brain requires good anesthesiology and adequate hemostasis is difficult to achieve. ${ }^{15)}$ Craniotomy in young infants requires an appropriate team of experienced personnel.

We operated on our patient because of the deterioration in consciousness and the finding of left hemiparesis in the emergency room. The hematoma was evacuated without difficulty during hemostasis. Patients treated by surgery at an early stage have had variable outcome. ${ }^{14)}$ Neurological examination in our patient at age of 13 months was normal except for very slight left hemiparesis. The indications for surgical treatment are controversial, because the significance of surgical intervention is difficult to establish due to the lack of studies on the use of sur- 
gery in this disease. Intracerebral hemorrhage may have effects on long-term development, so further investigation is needed to establish whether surgical treatment is more important than previously thought.

\section{References}

1) Balériaux D, Ticket D, Dony D, Leanmart L: The contribution of CT to perinatal intracranial hemorrhage including that accompanying apparently uncomplicated delivery at full term. Neuroradiology 19: 273-277, 1980

2) Bergman I, Bauer RE, Barmada MA, Latchaw RE, Taylor HG, David R, Painter MJ: Intracranial hemorrhage in the full-term neonatal infant. Pediatrics 75: 488-496, 1985

3) Cartwright GW, Culbertson K, Schrener RL, Garg BP: Changes in clinical presentation of term infants with intracranial hemorrhage. Dev Med Child Neurol 21: 730-737, 1979

4) Chaplin ER Jr, Goldstein GW, Norman D: Neonatal seizures, intracerebral hematoma, and subarachnoid hemorrhage in full-term infants. Pediatrics 63: 812-815, 1979

5) Fenichel GM, Webster DL, Wong WKT: Intracranial hemorrhage in the term newborn. Arch Neurol 41: 30-34, 1984

6) Furie BC, Furie B: Vitamin K: metabolism and disorders, in: Hematology: Basic Principles and Practice. New York, Churchill Livingstone, 1995, pp 17371741

7) Hanawa Y, Maki M, Matsuyama E, Tada H, Urayama T, Yamada K, Mori H, Nagao T, Terao T, Mikami S, Shiraki K, Onishi S, Shirahata A, Tsuji Y, Motohara K, Tsukimoto I, Sawada K: The third nationwide survey in Japan of vitamin K deficiency in infancy. Acta Paediatr Jpn 32: 51-59, 1990
8) Hanigan WC, Morgan AM, Anderson RJ, Bradle P, Cohen HS, Cusack TJ, Thomas-McCauley T, Miller TC: Incidence and neurodevelopmental outcome of periventricular hemorrhage and hydrocephalus in a regional population of very low birth weight infants. Neurosurgery 29: 701-706, 1991

9) Hanigan WC, Powell FC, Miller TC, Wright RM: Symptomatic intracranial hemorrhage in full-term infants. Childs Nerv Syst 11: 698-707, 1995

10) Hanigan WC, Powell FC, Palagallo G, Miller TC: Lobar hemorrhage in full-term neonates. Childs Nerv Syst 11: 276-280, 1995

11) Leblanc R, O'Gorman AM: Neonatal intracranial hemorrhage. J Neurosurg 53: 642-651, 1980

12) Meidell R, Marinelli PV, Randall V, Pettett G: Intracranial parenchymal hemorrhage in a full-term infant. An unusual clinical presentation with ultrasonographic diagnosis. Clin Pediatr (Phila) 22: 780783, 1983

13) Miller GM, Black VD, Lubchenco LO: Intracerebral hemorrhage in a term newborn with hyperviscosity. Am J Dis Child 135: 377-378, 1981

14) Nanba E, Eda I, Takashima $S$, Ohta S, Ohtani $K$, Takeshita K: Intracranial hemorrhage in the full-term neonate and young infant: correlation of the location and outcome. Brain Dev 6: 435-443, 1984

15) Sandberg DI, Lamberti-Pasculli M, Drake JM, Humphreys RP, Rutka JT: Spontaneous intraparenchymal hemorrhage in full-term neonates. Neurosurgery 48: 1042-1049, 2001

Address reprint requests to: S. Yokoyama, M.D., Division of Neurosurgery, Okinawa Chubu Hospital, 281 AzaMiyazato, Gushikawa, Okinawa 904-2293, Japan. e-mail: yokoyama_shunichi@hosp.pref.okinawa.jp. 